\title{
An Optimized PV based Plug-in Hybrid Electric Vehicle Charging Station Using Fuzzy-PI Controller Logic
}

\author{
Mariyaraj Daniel PRADEEP ${ }^{1 *}$, Shanmugavel Muthaiya RAMESH ${ }^{2}$, Balasubramanian GOMATHY \\ ${ }^{1}$ Anna University, Chennai, Tamil Nadu, India \\ dr.danielpradeep@gmail.com (*Corresponding author) \\ ${ }^{2}$ Department of Electronics and Communication Engineering, \\ KPR Institute of Engineering and Technology, Coimbatore - 641407, Tamil Nadu, India \\ drsmramesh@gmail.com \\ ${ }^{3}$ Department of Computer Science Engineering, \\ KPR Institute of Engineering and Technology, Coimbatore - 641407, Tamil Nadu, India \\ gomramesh@gmail.com
}

\begin{abstract}
The multi-port charging station for EV application is being widely used nowadays. The renewable energy-based charge generation schemes are employed with various controlling and optimization algorithms. The conventional method is applied with a PI controller based inverter circuit for accessing the PV grid-connected system interconnected with a charging station. Here the gating pulse is generated through Sinusoidal Pulse Width Modulation (SPWM) and it is controlled with a PI controller. The main objective of the proposed method is to increase the percentage of the State of Charge (SoC) and improve the grid utility circuit so that it could utilize a large load. In the proposed work, the optimized circuit of the PV grid system is designed by using Particle Swarm Optimization and the controller of the inverter circuit utilizes the Fuzzy based PI logic, then it generates the gate signal by Pulse Width Modulation Generator. The system is designed based on the utility grid and the EV capacity and the inverter block plays a vital part in this circuit. The controlling technique of the inverter improves the results by activating the charge depending on the load demand. The proposed PSO technique is improved through frequency scaling activation and the maximum power point tracking approach. The experimental results show the state of the utility charge by inverter, State of Charge, DC link voltage, PV tracking range and EV charging current. Thus, it can be concluded that the proposed work has achieved better results than other existing works by the design of the above-mentioned optimized PV model. The overall design model is performed with the help of the 2018a version of MATLAB/Simulink.
\end{abstract}

Keywords: PV generation, Fuzzy-PI controller, State of Charge, Proposed PSO with MPPT, Grid utility and EV charging station.

\section{Introduction}

In recent years, vehicle usage has increased day by day and it is designed with various accessible sources like petrol, diesel, fuel, electric charges, etc. As such, the electric vehicle usage has also increased recently and it motivates the researchers to develop new models with various processes. Power quality management with fuzzy logic is presented in (Ray, Das \& Mohanty, 2019). Hybrid EVs application with multi-port converter logic is discussed in (Akar et al., 2015). The PV charging station is presented in (Tazay \& Miao, 2018). The DC-DC converter has high voltage gain and the capacity of conveying control over a wide scope of voltage utility on EVs. Voltage Source Inverter controlling of PV charging station is controlling the battery by means of three-phase inverter logic and fault grid analysis (Merabet, Labib \& Ghias, 2018). The Hybrid Vehicle DC-DC converter is needed to increment the low unregulated electric source voltage to an exceptionally directed level by renewable energy source vitality. Fuzzy logic with PI control of switching activity is fed with PV and it is optimized using genetic algorithm in (Neath et al., 2014). The multi-port inverter logic control is presented with the hybrid sources (Rezaei et al., 2018). This ability is the primary factor in estimating future interest for EVs. Potential difficulties could be the establishment of a Distributed Generation system close to the quick charging station site, and hybrid vehicle with power management system is presented in (Mamadou et al., 2010). The voltage regulation and grid stability are controlled with PI and Fuzzy system. Various improvements have started to change the essentials of the activity of the electrical network industry prompting the ascent of DGs. In any case, the kind of vitality utilized in energizing the DG sources on the grid side is a conclusive factor in the financial feasibility of the DGs model (Kreeumporn \& Ngamroo, 2016). Type 1c Frequency Locked Loop with frequency drifting in converter is presented. Islanded mode of microgrid operation is performed for this evaluation (Beshr et al., 2021). The DC-DC converters with MPPT - PV renewable energy generator system in microgrid systems are presented in (Zhou, Ho \& Siu, 2019). The electric vehicle charging station uses wind and solar generation system. Hybrid electric vehicle energy systems with dual port converters are presented with PV (Monteiro et al., 2018). Flexible energy sources on the multi-port inverter 
logics are using PV sources (Gan et al., 2017). The fuzzy fractional controlling in grid system is optimized with gravitational search algorithm and multi-objective controlling in optimized variables utilizes the tuning parameters to activate the switching state of grid system. The storage unit of grid system is determining the demand utility system. The cascade multiport inverter logic is applied on the EV application of solar charging station, which is connected with Microgrid (Sun, $\mathrm{Wu} \& \mathrm{Hu}, 2019$ ). The plug-in hybrid electric resources are used for various logics; the interfacing of PV and wind generation system is modeled with various algorithms and techniques. The power management system for EV application is discussed in (Badawy \& Sozer, 2017). Sensorless power utilization and optimization is presented with the MPPT P\&O approach (Sher et al., 2015). Plug-in hybrid electrical vehicle with renewable energy resource is reviewed (ElNozahy \& Salama, 2015). Buck converter with PV MPPT logic is presented in (Venkatramanan \& John, 2019). MPPT-PV with double integral logic of grid system is presented in (Pradhan \& Subudhi, 2016). Various optimization algorithms and the controlling scheme using fractional-order PID and multi-objective gravitational search algorithms are reviewed. Plug-in hybrid EV system is analysed with various aspects of utilization and reviewed by Vyas et al. (2008). Cost function reduction in PSO approach, and EV charging station with battery storage systems are demonstrated (Yan, Zhang \& Kezunovic, 2017). Mutual coupling of switched inductance logic in grid model is presented in (Kabir \& Husain, 2016). In the proposed work, the PV charging station of EV charger and its multi-port connections are performed with novel controlling strategy. The Fuzzy logic controller with PWM gate pulse generator is controlled with switch logic IGBT transistors. The three-phase inverter of grid system is controlled with the PI controller and it is tuned to generate the PWM gate signals. The proposed charging station performs the logic controlling and the improvement of the State of Charge. The experimental results of PV output, inverter switching control, grid system output, utility grid, EV demand charger control and direct current link voltage are determined and compared with those in previous literatures.

The remainder of this paper is summarized as follows. Section 2 reviews the various works related to this research. Section 3 presents the existing works and the techniques they apply.
Section 4 proposes the Fuzzy based PI controller on PV grid connected system with optimized algorithm. Section 5 presents the experimental results and discussions. Section 6 concludes the proposed work and it also outlines possible future extensions of the proposed work.

\section{Literature Survey}

Tazay \& Miao (2018) proposed the three-phase hybrid converter control on the solar charging system. Crossover support converter has been designed to supplant a DC/DC converter and a DC/air conditioning converter to diminish transformation stages and exchanging of energy. Here the control of a three-stage boost controller in a PV charging station is planned to interface with a whole PV framework. The PV generation with maximum tracking of MPPT is interfaced with the grid to utilize the demand. The DC output voltage and inverter across the voltage helps one manage the reactive power. Analyzed results exhibit the achievability of the planned control design. At last, lab testing is performed to show HBCs control execution.

Neath et al. (2014) presented the Genetic algorithm based controlling technique on EV. The voltage control of partial request and direct power control are applied to the grid arrangement of an electric vehicle, which uses the PI. Recreation results show the effectiveness of the planned control and utility grid. These reproductions were completed utilizing the speed profiles given by the New European Driving Cycle. EV charging stations with utility grid are controlled with PI integrations.

Mamadou et al. (2010) presented the review of DCDC converter topology for electric vehicle charging station. In any case, the Sinusoidal Sufficiency Converter, the Z-Source DC-DC converter and the DC-DC converter with resounding circuit are more appropriate for low-power Bi-directional Electrical Vehicles and Plug-in Hybrid Electrical Vehicles due to their delicate exchanging, low exchanging misfortune and high efficiency.

Ray, Das \& Mohanty (2019) have proposed the hybrid fuzzy logic control for electric vehicle applications like storage utility, demand control, energy management and so on. The multi-port logic control on the dc-converter is utilizing PI control. The energy tracking is determined by MPPT and the detailed model is tracked with 
the speed controls. Dynamic response of PV grid connected system is controlled on the motor speed control with multiple-inverter logics. The energy utilization is determined by output response and flexible resources. Power management techniques and switch controlling is done by fuzzy and PI logics. This hybrid system is utilizing solar and wind generator with multi-port converter.

\section{Existing Work}

The conventional method utilizes PV module, DC-DC Buck Boost converter with Perturb \& Observe - MPPT approach for getting maximum power peaks of PV panel, and the SPWM inverter controls the charging state by varying phase shift options. The temperature and irradiance of PV generates the power and it is tracked with MPPT along with $\mathrm{P} \& \mathrm{O}$ approach for utilizing maximum peak power. The Buck-Boost converter is used for EV and grid utility; Inverter controlling on Voltage Source Controller utilized the PI and SPWM controlling on duty cycles. The simulated result represents the result of PV source and electricity utilization circuit.

The conventional block diagram of PV based EV charging station is shown in Figure 1. The system interfaced with $\mathrm{AC}$ load on grid system and the multiple sources of plug-in resources are utilized to charge the EV battery. The drawback of the existing work lies in controlling the inverter with fixed logics and variable loads. The system was designed to improve the State of Charge and the proposed method features an improved result of SoC.

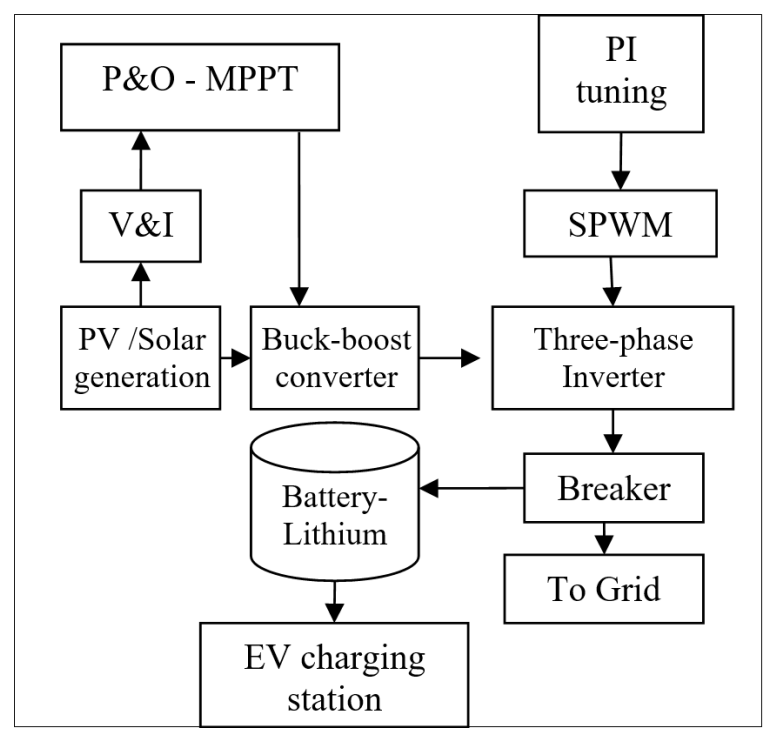

Figure 1. Conventional block diagram of PV based EV charging station

\section{Proposed Method}

The proposed PV based EV charging station is designed with improved controlling strategy of fuzzy and PI controller. Here the pulse width modulation signal generates the gating signal of inverter and converter block. In this manner, the machine is displayed in a lot of differential conditions with variable coefficients. Based on the value of irradiance and temperature, the PV generates the power and maximum power peak is tracked to utilize the charging station. Here the PSO optimizes the voltage and current of PV; maximum power peak is tracked and controlled by PWM with fuzzy and PI controller logic. The block diagram of the proposed logic controlling of EV charging station is illustrated in Figure 2.

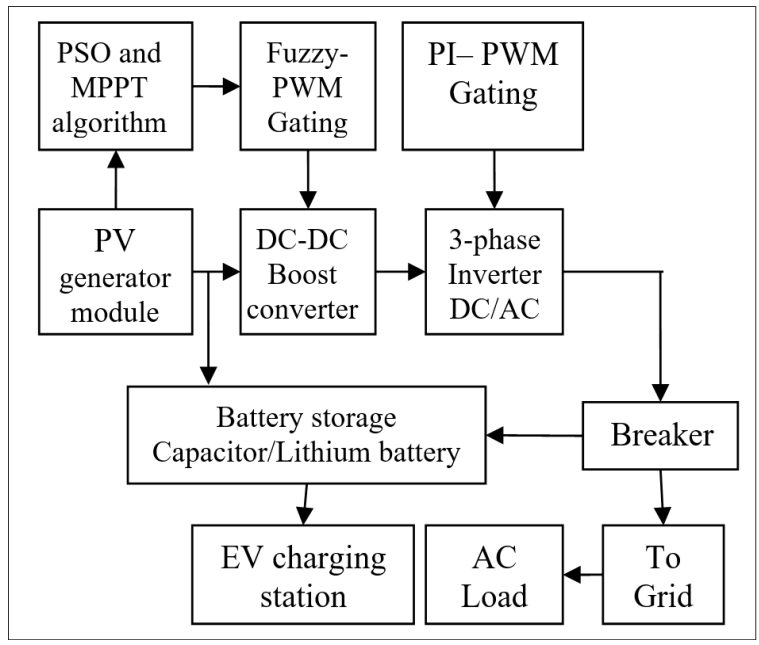

Figure 2. Block diagram of the proposed model of optimized PV based EV charging station

The DC-DC boost converter is used on the PHEV power trains and in charging station. Nonetheless, the future patterns of DC-DC converter exploration will plan to address the accompanying central points of contention. From this blocking flow, the proposed structure demonstrates the PV utility based charging station with fuzzy PI control logic. The PV integration uses MPPT and PSO; DC-DC Boost converter improves the PV voltage to the grid module via inverter, which is controlled with the PI controller. Gated pulse signal generated from the PWM and the converter control uses Fuzzy logic; here the crisp value of control state result from PSO, the binary value is mapped on to the fuzzy set then it is defuzzified with opposite conversion of fuzzification like an inverse process. Fuzzy set is selected with the inference rule based on optimized result of voltage utility and 
duty cycle. The improvement in combination of Fuzzy and PI logic controller is applied on the converter and inverter module with PWM signal generator. The duty cycle obtains the optimized value based on the PV generation and the voltage source conversion model performed with utility power. Therefore, the proposed combination of two controllers with logic on converter and inverter improves the results by utilizing EV based charging station. When the switching of DC_DC boost converter is $\mathrm{ON}$ the voltage will be,

Vin - Vload $=0$

If the switching of boost converter is OFF, the voltage will be:

Vin - Vpv $=$ Vload

$$
\text { Dutycycle }=1-\mathrm{Vin} / \mathrm{Vpv}
$$

where, Vin represents input voltage, $V_{\text {load }}$ represents voltage of load and $\mathrm{Vpv}$ represents the voltage of PV. Besides, the high-constancy model of DC-DC converter means to configure approve and distribute a proposal about standard interfaces for cutting-edge engineers.

In the DC-DC stage converter, the 3-stage bridgeless boost converter has a negligible number of segments. LC filter on the PV grid is given by,

$$
\begin{aligned}
& L=\frac{(1-D) V p v}{f \Delta \mathrm{I} m} \\
& C=\frac{D^{*} I p v}{f \Delta V p v}
\end{aligned}
$$

Where, $\Delta I m$ represents the change of MPPT current, $\triangle V p v$ represents the change of $\mathrm{PV}$ voltage in MPPT logic, D denotes duty cycle and Ipv denotes current of PV module. Here the 3-stage diode rectifier requires a direct control method in comparison with other converters in the DCAC stage which are utilized with AC load and the control strategy is contrasted with that of other converters in the DC-DC stage. Both 3-level 3 -stage inverter and DC-DC converter are more reliable in the exchanging circuit and are prepared to perform high-control change. Both 3-stage diode rectifier and multiple boost converters have a straightforward design with higher effectiveness and dependability. Be that as it may, multiple interleaved boost converters contain high-stage current THD.

\section{a. PV generator}

The solar energy generation of grid circuit takes place by utilizing EV applications. Energy storage and management circuits are tracking the PV power by PSO with MPPT algorithm. The PV is considered to be a successful arrangement, because of its manageability and distributions to EV application. The grid-connected PV models are used with more profound infiltrating levels contrasted with the irradiance and temperature values. This is because of the ceaseless dependence on the electric matrix as a steady source/load that can make up for the PV power (Ppv) changes.

$$
P p v=V p v^{*} I p v
$$

Optimal value of PV range is selected with the particle swarm optimizer and it is selecting the optimized value to the MPPT. Here the DC-DC boost converter is utilized on the grid circuit to boost the voltage ' $V d c$ '.

The overall Simulink model (see Figure 3) of optimized PV grid-connected system for EV charging station is created to achieve better results in comparison with the previous fuzzy control based Multi-Level Inverter (MLI). Maximum voltage and current generations are applied on the MPPT algorithm to track the maximum power with respective irradiance-and temperaturedependent source. From this maximum power is optimized and switched with the V_pv, I_pv and Vdc. The PV utility with fuzzy and PI controller generates the active and deactive pulses based on the optimized results from PSO. Here the MPPT tracking of the maximum utility power depends on the irradiance and temperature. By means of MPPT the PSO optimizes the results by generating the active particle which is the requirement of EV and battery storage unit.

\section{b. Fuzzy for converter control}

The regulator manages the DC-interface capacitor voltage as indicated by the reference voltage $(\mathrm{Vdc}=\mathrm{Vpv})$, chose by the MPPT plot. The DC-interface voltage guideline is met through the control of direct current, which as a result, controls the maximum power infusion into the EV charging station. Both the process of fuzzification and defuzzification generate the crisp value and fuzzy set, which is selected with the rules of inference. A voltage measure of $\mathrm{PV}$ is the source 


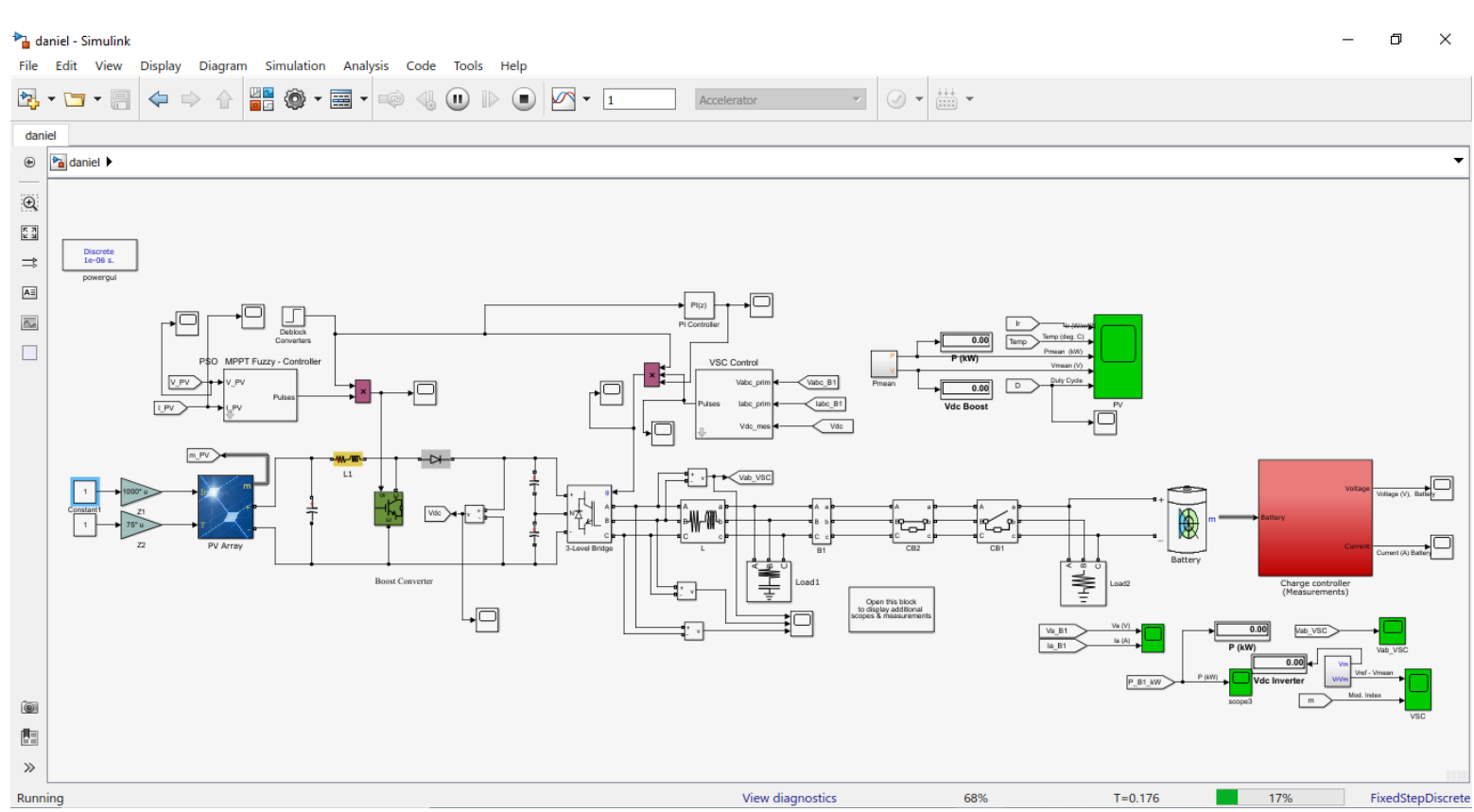

Figure 3. Simulink model of the proposed work

value for the crisp set and it selects the pulses from the rule-based optimization results. This approach performs the decision making of PSO and generates the pulses by using PWM.

c. PI for Three-phase inverter control

Microgrid can be controlled to work in either independent mode or lattice asSoCiated mode. The MG is associated with the utility through a voltage source converter via a three-stage inverter.

$G f(s)=K p+\frac{K i}{s k}+K d^{s n}$

where $\mathrm{n}$ and $\mathrm{k}$ are the range of controlling state with steady state performance. Corresponding essential (PI) regulators have an adequate conduct when managing DC factors consequently PI compensators are utilized for the control. The values of $\mathrm{Kp}$ and $\mathrm{Ki}$ depend on the gain function of $\mathrm{P}$ and I performances, which identifies the fixed determination that is $\mathrm{Kp}$ and $\mathrm{Ki}$ for the inverter logics and selects the pulses with PWM generator. Depending on the EV utility, the MG is designed to get the better result of PV voltage in the form of two sources that is battery and load. Inverter voltage Vab-bc-ca denotes the controlled value from PI that is connected with the VSC and direct source of PV output is given on battery. A generated source of $200-1000 \mathrm{~V}$, and $380-480 \mathrm{~V}$ is used for EV application.

\section{d. Proposed PSO with MPPT on PV}

It is a meta-heuristic based optimization technique that can be applied to advancement issue to identity the ideal point. In every cycle, each PVvoltage is quickened toward the molecule's past best position (pbest) and the worldwide best position (gbest). In PSO, the particle position declaration is given as,

$x n=(x 1 n, x 2 n, \ldots . . x d n, \ldots X n) n=1,2,3 . . N$

Here the fitness evaluation and particle position declarations are given by,

$$
\begin{aligned}
& \left\{m_{f i t}(t n)=\frac{f i t(t n)-\operatorname{worst}(t n)}{\operatorname{best}(t n)-\operatorname{worst}(t n)}\right\} \\
& \left\{\begin{array}{l}
\operatorname{best}(t n)=F i t_{\text {min }}(t n) \\
\operatorname{Worst}(t n)=F i t_{\text {max }}(t n)
\end{array}\right\}
\end{aligned}
$$

Where, best $(\operatorname{best}(t n))$ and worst $(\operatorname{worst}(t n))$ particles are updated with 'tn' iterations. Here, worst case and cycle is at that point, iterated a set number of times or until a base blunder is accomplished. The random value selection by frequency scaling is given.

$$
\text { Fit }_{\text {rand }}(t n)=\sum_{i=1}^{N} \text { randFit }_{i}(t n)
$$

Velocity updating on PSO is expressed as

$$
\operatorname{Vi}(t n+1)=\operatorname{rand} v_{i}(t n)+f i t(t n)
$$


Various steps to process the proposed PSOMPPT for PV grid-connected system are utilized. Flowchart of the MPSO_MPPT algorithm on PV grid system is given in the Figure 4.

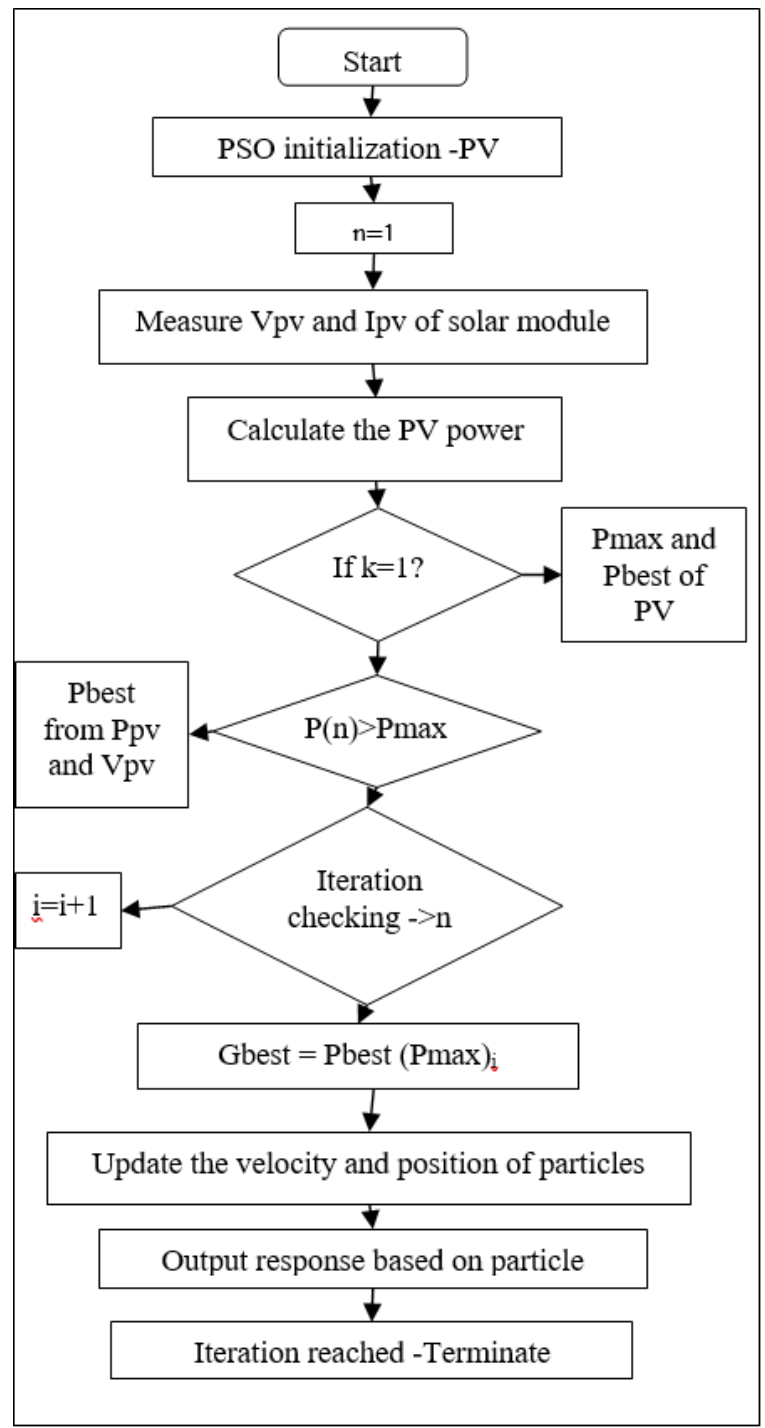

Figure 4. Flowchart of the proposed MPSO with MPPT

Maximum voltage and current generations are applied on the MPPT algorithm to track the maximum power with respective irradiance and temperature-dependent source. From this maximum power is optimized and switched with the Vpv, Ipv and Vdc. The PSO strategy which is utilized for the MPPT technique in this investigation depends on the PV. The selection of PSO shows the better performance state and it determines the optimized result to get the minimum loss and better utility. This gradient approach based on natural inspiration model shows the well-recognized state of particle and with the DC_DC boost converter using Fuzzy PWM combinations better results are obtained.
The utility of maximum voltage value is applied on the PSO to get the required energy as optimized result.

\section{e. Charging station}

The electric vehicle charging station utilized the power by multiplying PV grid voltage and current. Here the energy delivered from the battery over the grid is derived as,

$$
E_{\text {deliver }}=\int_{0}^{t} P_{d c} d t
$$

State of Charge in the EV application based PV grid-connected system is expressed as,

$$
\begin{aligned}
& S O C(t n)=S O C(t n-\Delta t n)-\frac{P g(t) \Delta t n}{Q} \\
& S O C_{\min } \leq S O C(t n) \leq S O C_{\max }
\end{aligned}
$$

The percentage of $\mathrm{SoC}$ is calculated to achieve the best result as compared to the existing works. Thus the design model of PV based EV charging station is designed with the controlling technique and optimization algorithm. The system achieves the State of Charge result of $99.8 \%$. The system achieves an efficient result of PV grid voltage, $\mathrm{Vdc}$ and power.

\section{Results and Discussion}

Thus the design model of proposed PV grid circuit for EV charging station using PSO algorithm is designed to improve the results. Here the fuzzy and PI controllers are used on the controlling block of converter and inverter. Here the lithium battery and AC load is utilized to identify the satisfied demand request of energy. Here the results of PSO-MPPT optimization of PV, fuzzy-PWM switching of DC-DC Boost converter, PI-PWM switching for three-phase DC-AC inverter block, PV grid, utility grid and batter charging station are analyzed. The output response of $\mathrm{PV}$ voltage and current is given in Figures 5 and 6, respectively.

The duty cycle of PV grid system is shown in Figure 7. Here the Proposed frequency scaling dependent PSO approach takes the Vpv and Ipv as input and it is processed with the MPPT; depending on this, the fuzzy logic controller controls the grid utility as switching factor by PWM. The maximum power tracking with 


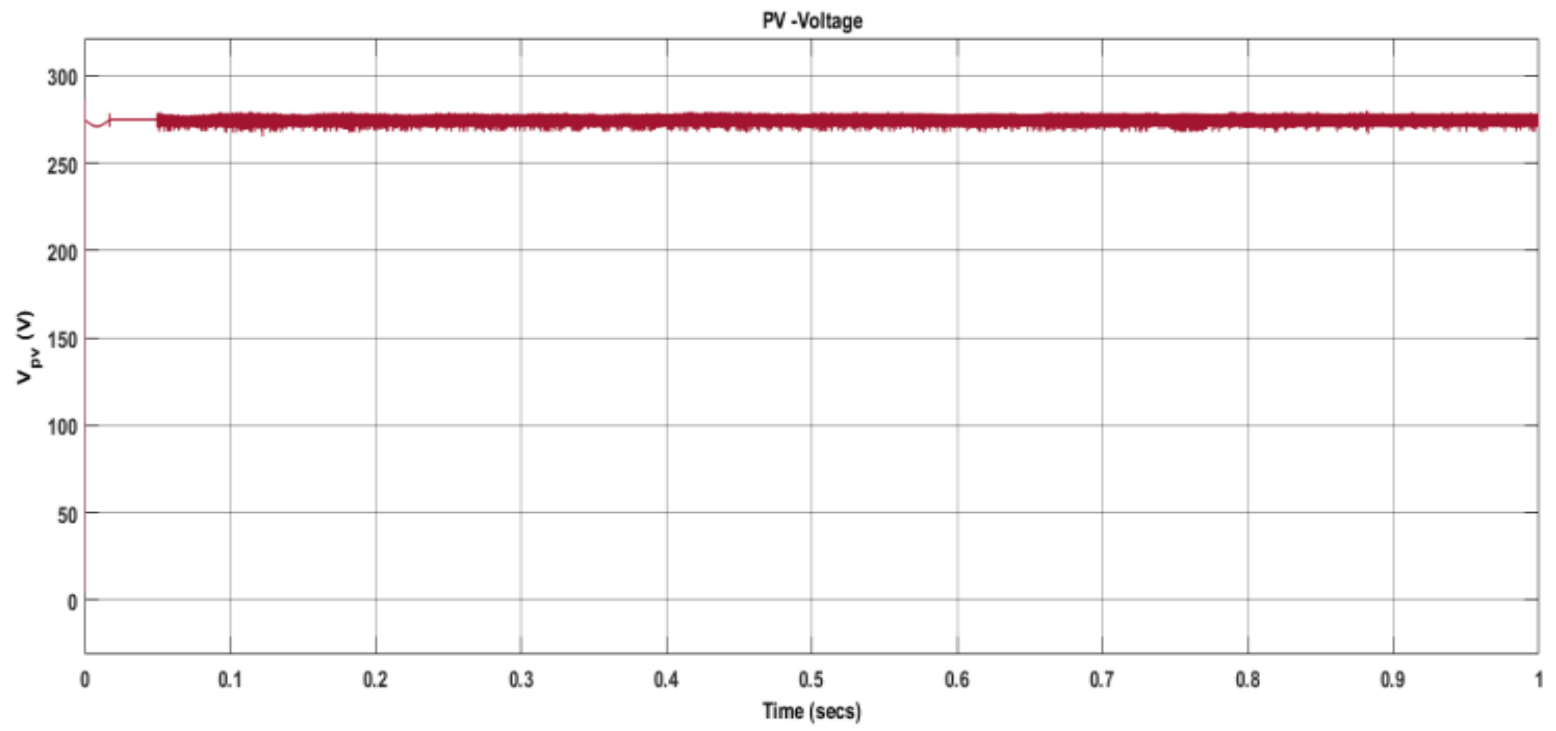

Figure 5. PV output voltage response

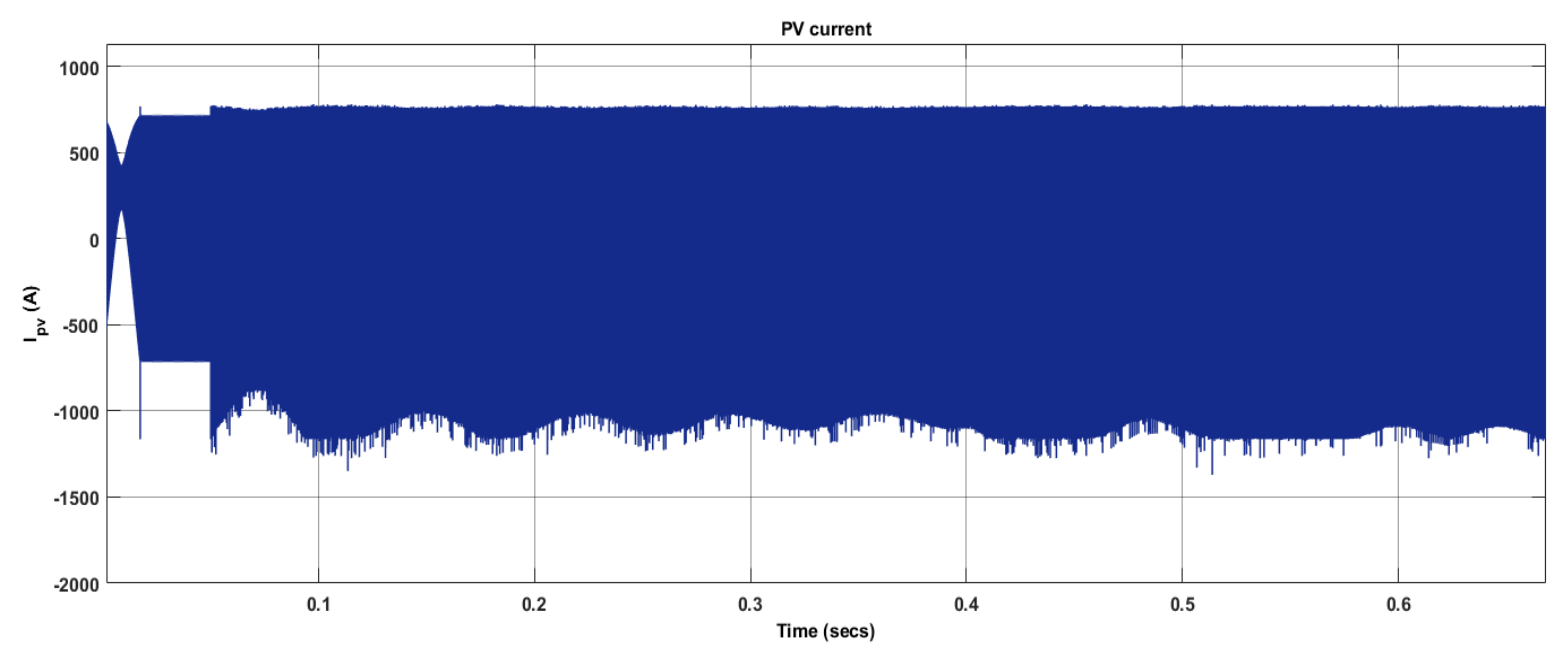

Figure 6. Output current response

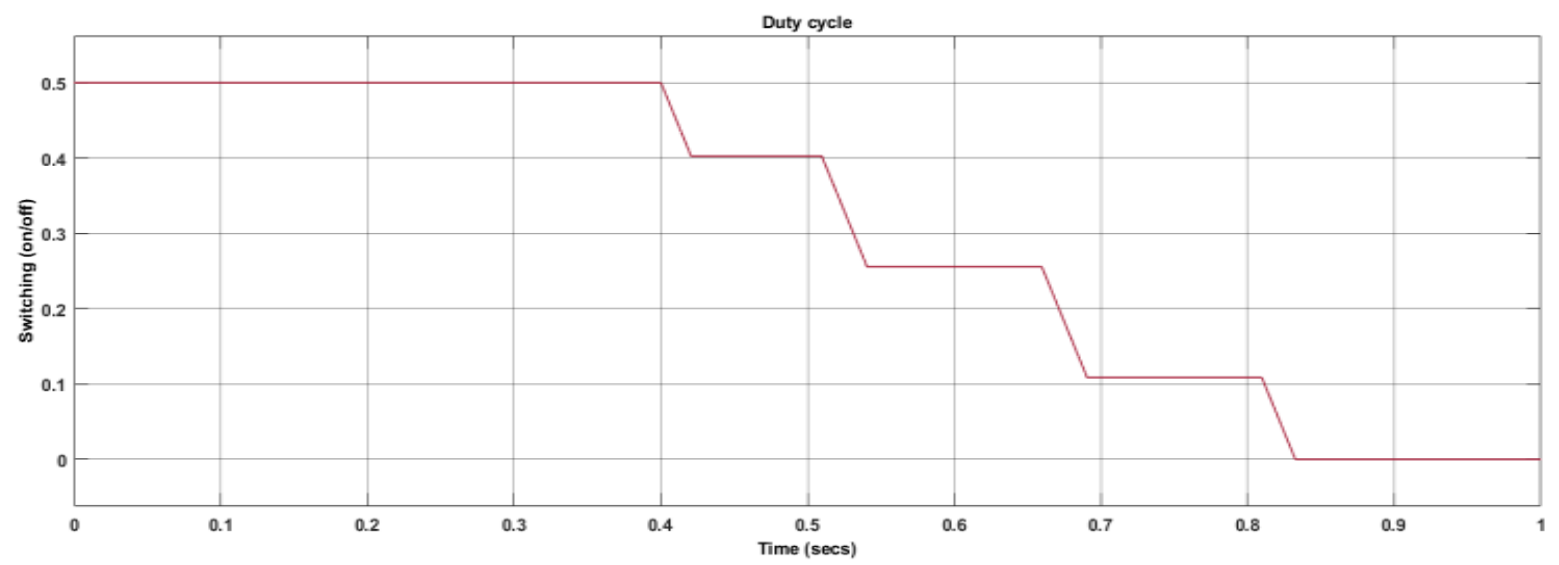

Figure 7. Duty Cycle state 
switching control that is $\mathrm{P}(\mathrm{kW})$ is given in Figure 8.

After receiving the switching state from $\mathrm{PSO}$ MPPT with Fuzzy controller, the PWM generates the gating signal and it boosts the DC link voltage. The simulated result of DC link voltage is given in Figure 9.

Here the three-phase inverter with switching logic is controlled by PI tuning, which is fed with the grid system and it is converted into the DC to AC. Voltage across inverter in the terminals of ab-bc-ca is given in Figure 10. The utility on MPPT and modulation index is given in Figure 11. The Vdc utilized on the grid system is stored on the battery; here the Lithium battery is used to store the energy for EV application. In PV generator, the ultracapacitor stores the energy for direct charging and discharging. Here the battery is used for energy storing otherwise the multiport logic is used for charging the Electric Vehicles. The battery charging station's usage after AC load connection provides battery current, and battery voltage. Simulated result of EV charging station is shown in Figures 12 and 13.

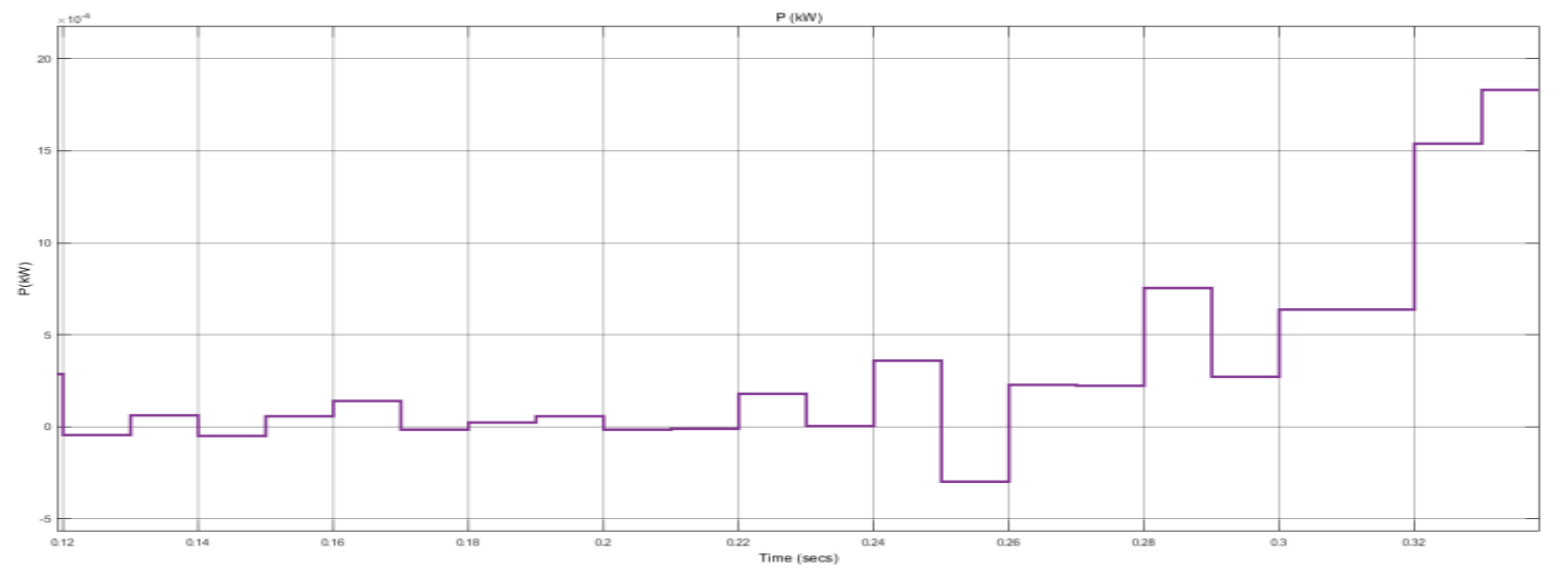

Figure 8. Maximum power tracking of PV

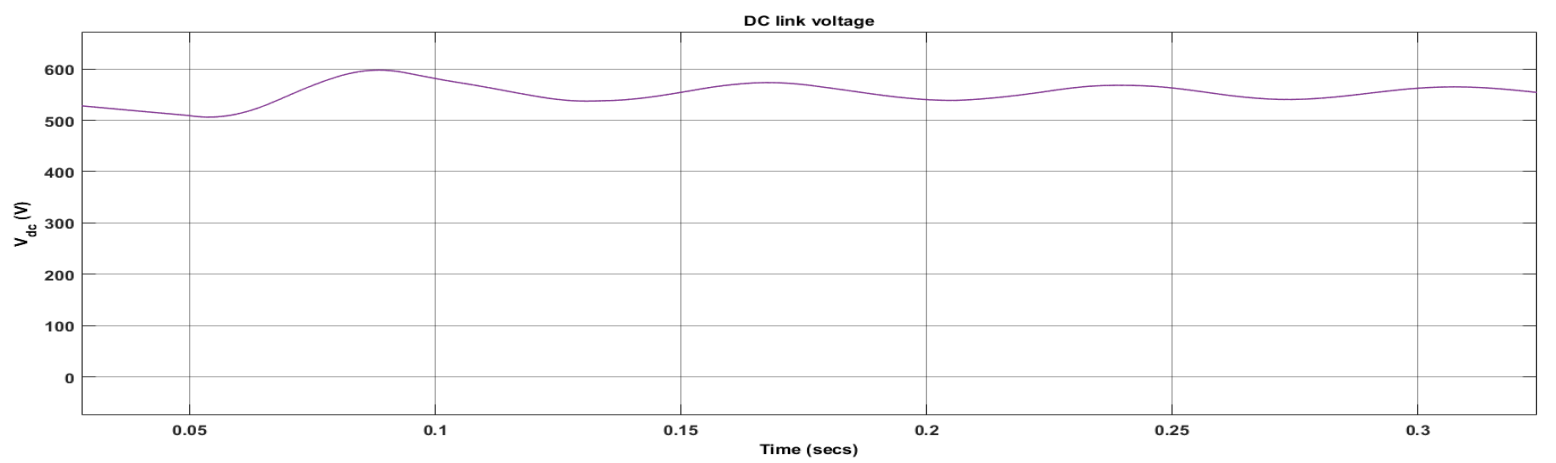

Figure 9. DC link voltage

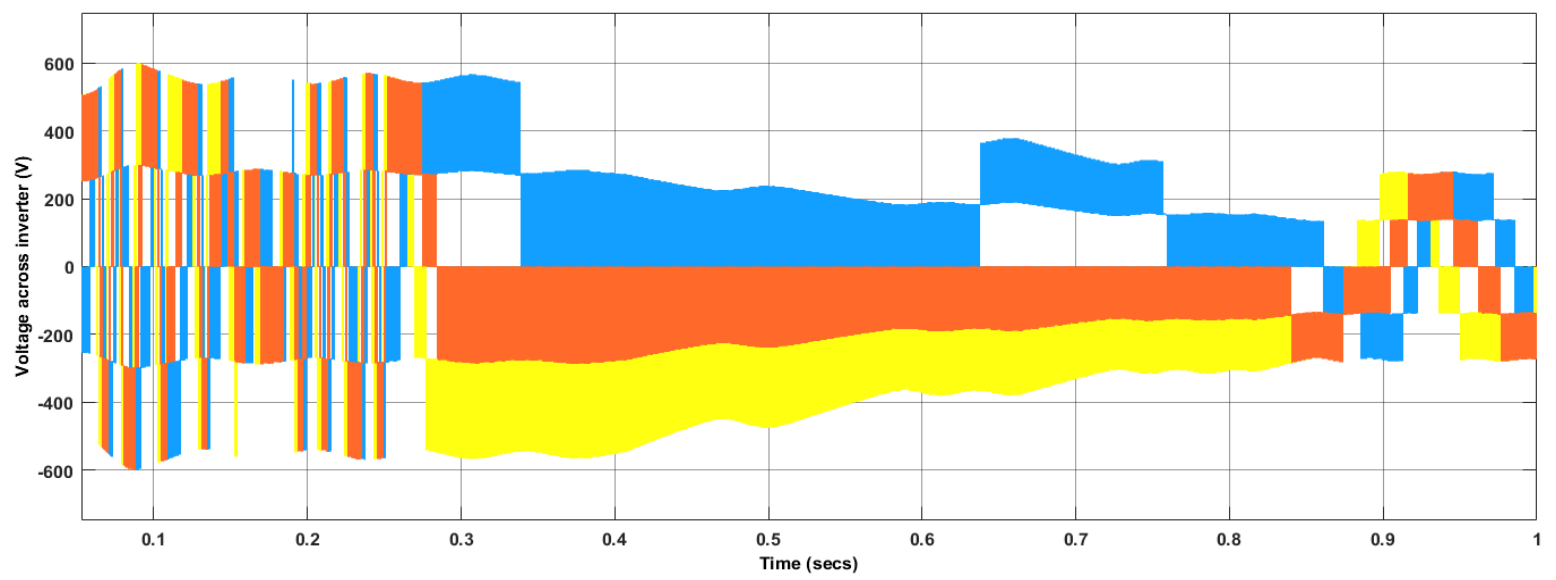

Figure 10. Voltage across inverter Vab-bc-ca 

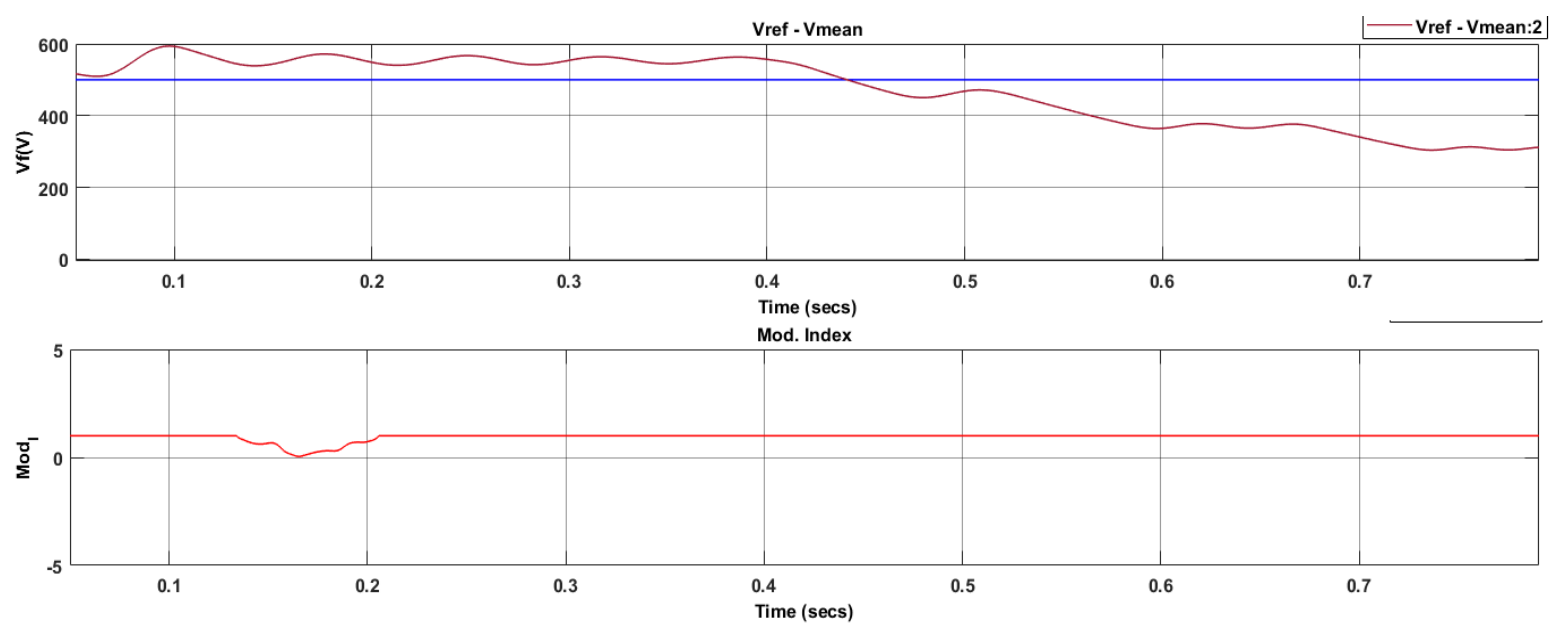

Figure 11. Voltage tracking of MPPT - PV grid

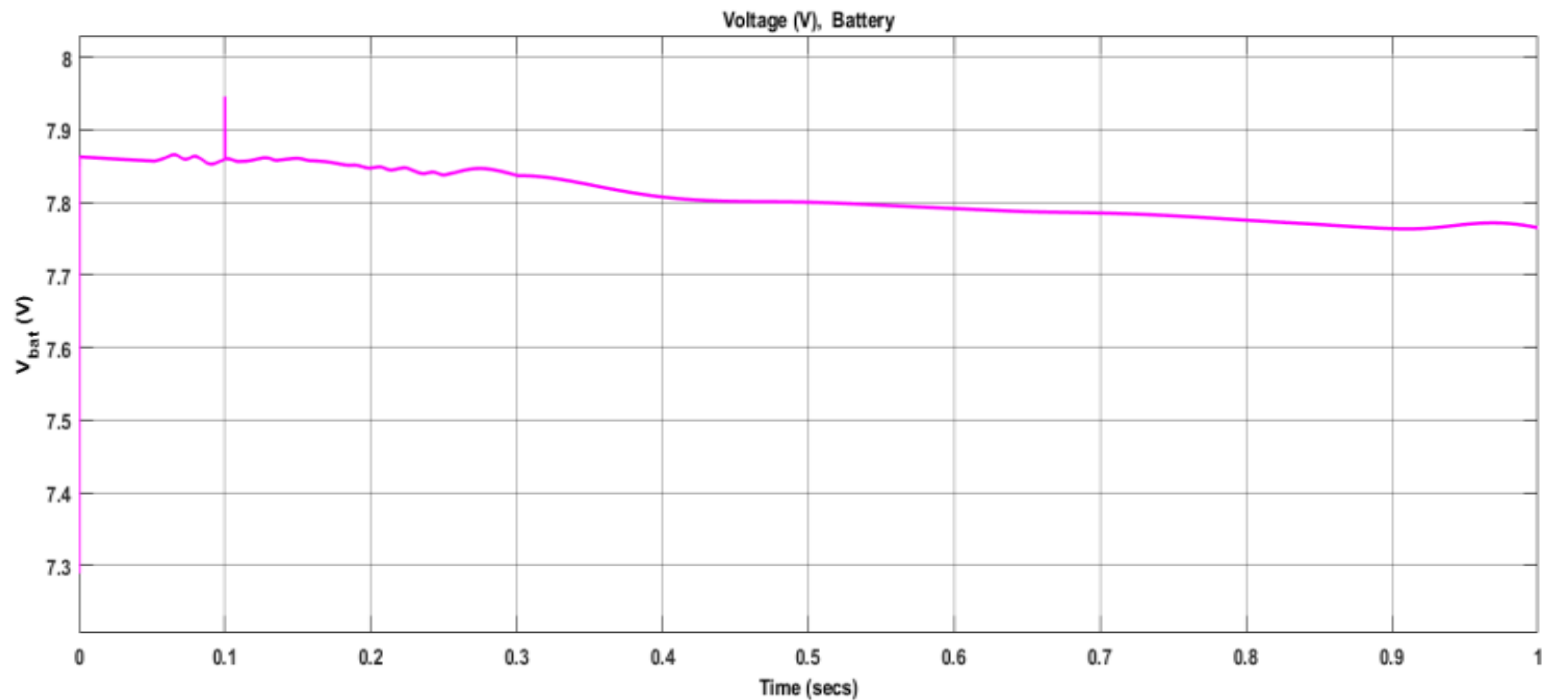

Figure 12. Battery charging -Voltage

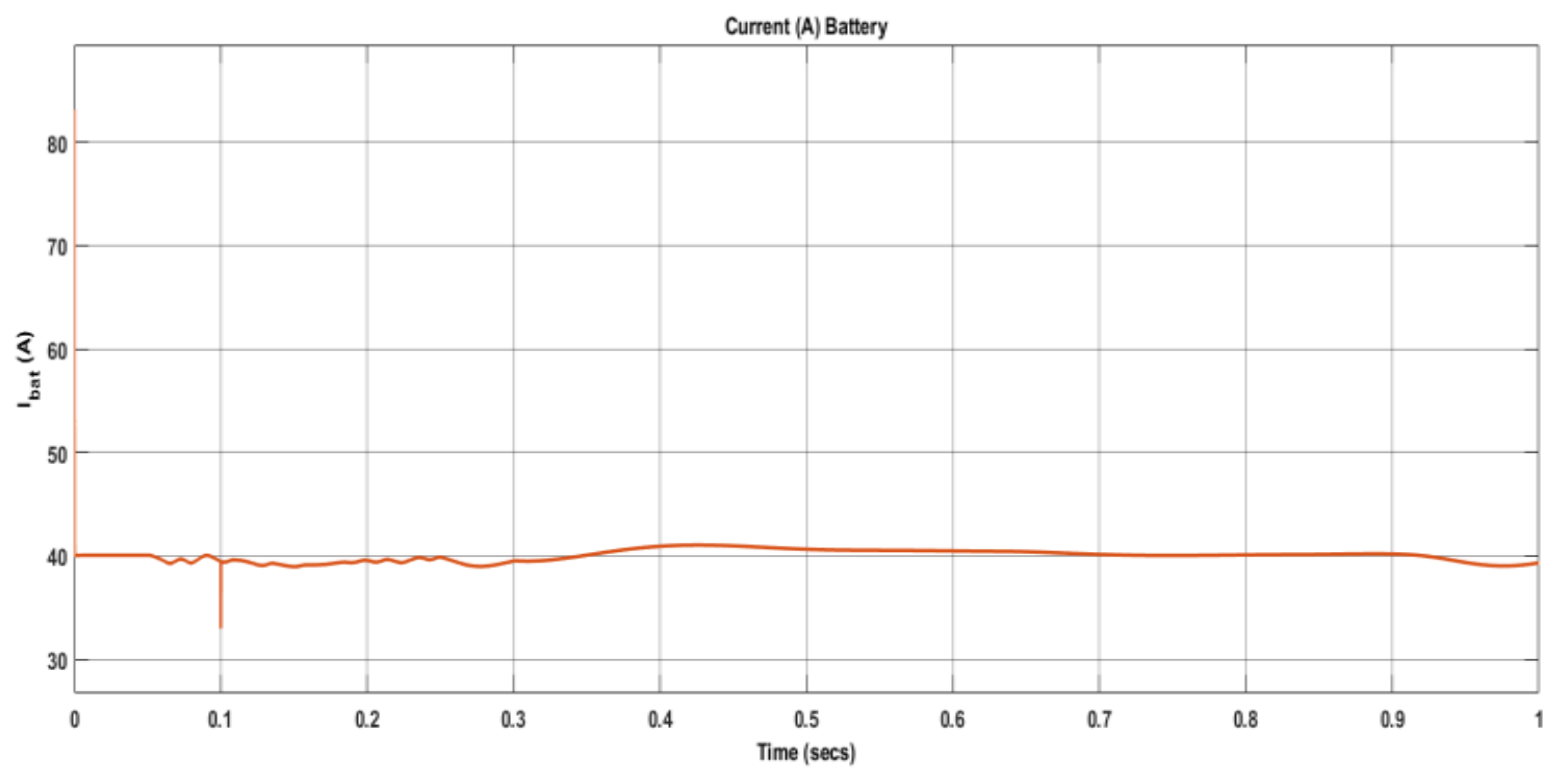

Figure 13. Battery charging - Current 


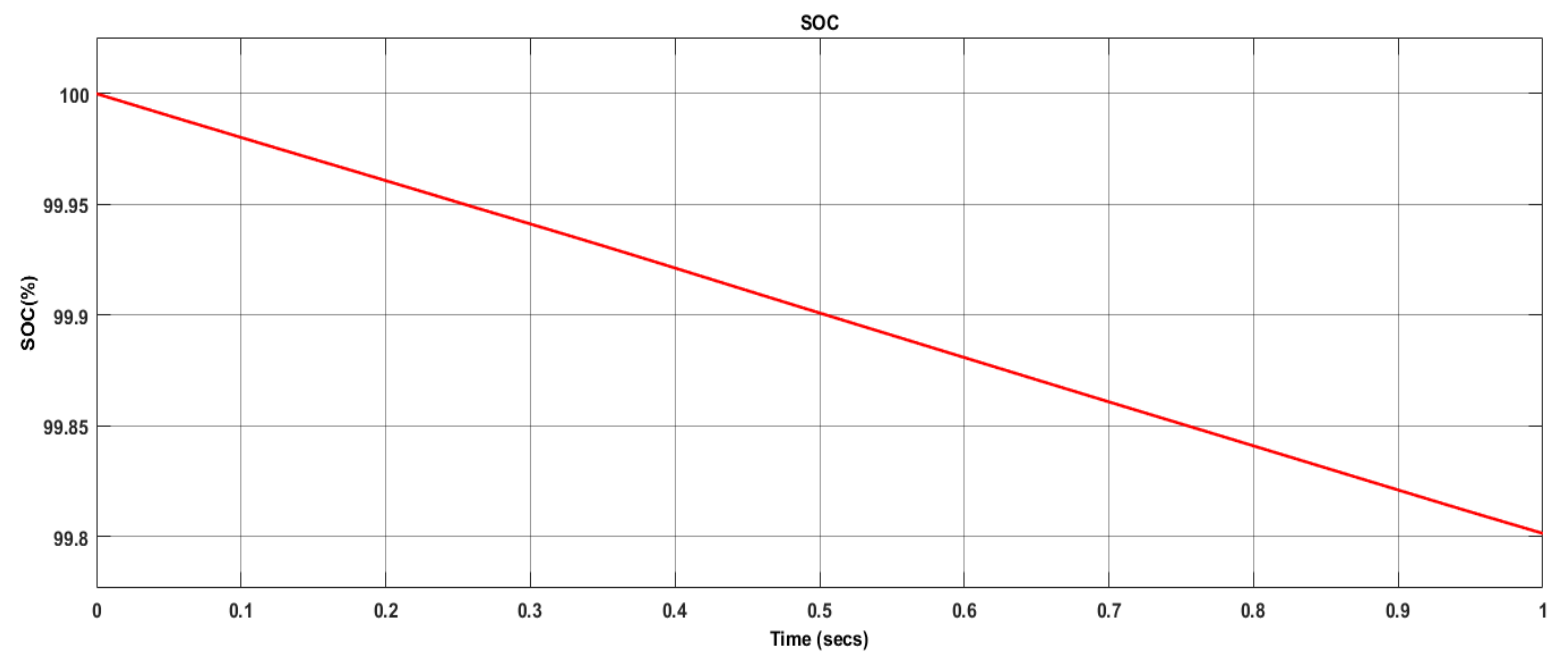

Figure 14. Percentage of State of Charge

Table 1. Comparison of results

\begin{tabular}{|c|c|c|c|c|}
\hline Parameter & $\begin{array}{c}\text { Existing work } \\
\text { (Anant et al., 2008) }\end{array}$ & $\begin{array}{c}\text { Existing work } \\
\text { (Chun Gan et al., 2017) }\end{array}$ & Previous work & Proposed work \\
\hline SoC & $89 \%$ & $90.48 \%$ & $99.4 \%$ & $99.8 \%$ \\
\hline Vdc & $112 \mathrm{~V}$ & $384 \mathrm{~V}$ & $500 \mathrm{~V}$ & $550 \mathrm{~V}$ \\
\hline PV voltage & $110 \mathrm{~V}$ & $150 \mathrm{~V}$ & $280 \mathrm{~V}$ & $290 \mathrm{~V}$ \\
\hline Grid utility & $415 \mathrm{~V}$ & $600 \mathrm{~V}$ & $600 \mathrm{~V}$ & $800 \mathrm{~V}$ \\
\hline EV current & $100 \mathrm{~A}$ & $17.5 \mathrm{~A}$ & $188 \mathrm{~A}$ & $190 \mathrm{~A}$ \\
\hline
\end{tabular}

In the proposed work, the result of SoC shows the better optimized PV grid-connected systems with Fuzzy-PI. Generated gating signal with PWM is designed to get efficient results. Here the DC-DC Boost converter is used on the PV grid-connected system, which is utilized with the battery charging station of EV. The percentage of SoC is given in the Figure 14. The comparison of results illustrates the performance of five different parameters, which is shown in Table 1.

In this paper, the optimized PV grid-connected system is designed with novel strategy to improve the overall performance of SoC. Here the PV module generates the power and tracks the maximum power to utilize the grid system. Based on this comparison the results related to the SoC, Vdc and PV voltages are the best.

\section{Conclusion and Future Scope}

Thus, it can be concluded that the optimized design model of the PV grid-connected system utilized for EV charging station obtains better results. Here the use of direct loading strategy and battery storage unit helps one charge the required EVs and provided the better result of SoC. Based on the utility grid, the circuit is designed to map the converter and inverter logic controls. Here the Fuzzy logic controller contributes to the improvement of the switching state by generating the gate pulses from PWM. The PI controller tunes the value of $\mathrm{Kp}$ and $\mathrm{Ki}$ for controlling the three-phase inverter by PWM. Initially, full charging state is reached after charging the capacitor. Therefore the result for the State of Charge improves the system performance by grid utility. In comparison with various existing works, the proposed work achieved the best results. In the future, this work may be extended by various applications in EV like charging port, energy management and EV motor driving systems. 


\section{REFERENCES}

Akar, F., Tavlasoglu, Y., Ugur, E. Vural, B. \& Aksoy, I. (2015). A Bidirectional Nonisolated Multi-Input DCDC Converter for Hybrid Energy Storage Systems in Electric Vehicles, IEEE Transactions on Vehicular Technology, 65(10), 7944-7955. DOI: 10.1109/ TVT.2015.2500683

Badawy, M. O \& Sozer, Y. (2017). Power flow Management of a Grid Tied PV-Battery system for Electric Vehicle Charging, IEEE Transactions on Industry Applications, 53(2), 1347-1357. DOI: 10.1109/TIA.2016.2633526

Beshr, H. A., Moursi, M. S. E., Hamed, H. A. \& Al-Sumaiti, A. (2021). Advanced Type-1c FLL for Enhancing Converters Synchronization During Frequency Drift, IEEE Transactions on Power Delivery, 36(2), 1063-1078.

ElNozahy, M. S. \& Salama, M. M. A. (2015). Uncertainty-Based Design of a Bilayer Distribution System for Improved Integration of PHEVs and PV Arrays, IEEE Transactions on Sustainable Energy, 6(3), 659-674. DOI: 10.1109/TSTE.2015.2405411

Gan, C., Jin, N., Sun Q., Kong, W., Hu, Y. \& Tolbert, L. M. (2017). Multiport Bidirectional SRM Drives for Solar-Assisted Hybrid Electric Bus Powertrain With Flexible Driving and Self-Charging Functions, IEEE Transactions on Power Electronics, 33(10), 82318245. DOI: 10.1109/TPEL.2017.2780622

Kabir, M. A. \& Husain, I. (2016). Design of Mutually Coupled Switched Reluctance Motors (MCSRMs) for Extended Speed Applications Using 3-Phase Standard Inverters, IEEE Transactions on Energy Conversion, 31(2), 436-445.

Kreeumporn, W. \& Ngamroo, I. (2016). Optimal Superconducting Coil Integrated Into PV Generators for Smoothing Power and Regulating Voltage in Distribution System With PHEVs, IEEE Transactions on Applied Superconductivity, 26(7), 1-5.

Mamadou, B. C., Hamid, G., Frederic, G., Alain, B. \& Brayima, D. (2010). DC/DC Converter Design for Supercapacitor and Battery Power Management in Hybrid Vehicle Applications-Polynomial Control Strategy, IEEE Transactions on Industrial Electronics, 57(2), 587-597.

Merabet, A., Labib, L. \& Ghias, A. M. Y. M. (2018). Robust Model Predictive Control for Photovoltaic Inverter System With Grid Fault Ride-Through
Capability, IEEE Transactions on Smart Grid, 9(6), 5699-5709. DOI: 10.1109/TSG.2017.2694452

Monteiro, V., Ferreira, J. C., Nogueiras Meléndez, A. A., Couto, C. \& Afonso, J. L. (2018). Experimental Validation of a Novel Architecture Based on a DualStage Converter for Off-Board Fast Battery Chargers of Electric Vehicles, IEEE Transactions on Vehicular Technology, 67(2), 1000-1011. DOI: 10.1109/ TVT.2017.2755545

Neath, M. J., Swain, A. K., Madawala, U. K. \& Thrimawithana, D. J. (2014). An Optimal PID Controller for a Bidirectional Inductive Power Transfer System using Multiobjective Genetic Algorithm, IEEE Transactions on Power Electronics, 29(3), 1523-1531. DOI: 10.1109/ TPEL.2013.2262953

Pradhan, R. \& Subudhi, B. (2016). Double Integral Sliding Mode MPPT Control of a Photovoltaic System, IEEE Transactions on Control Systems Technology, 24(1), 285-292.

Ray, P. K., Das, S. R. \& Mohanty, A. (2019). FuzzyController-Designed-PV-Based Custom power quality enhancement, IEEE Transactions on Energy Conversion, 34(1), 405-414.

Rezaei, A., Burl, J. B., Rezaei, M. \& Zhou, B. (2018). Catch energy saving opportunity in charge-Depletion mode, a real-time controller for plug-in Hybrid Electric Vehicles, IEEE Transactions on Vehicular Technology, 67(11), 11234-11237. DOI: 10.1109/ TVT.2018.2866569

Sher, H. A., Murtaza, A. F., Noman, A., Addoweesh, K. E., Al-Haddad, K. \& Chiaberge, M. (2015). A New Sensorless Hybrid MPPT Algorithm Based on Fractional Short-Circuit Current Measurement and P\&O MPPT, IEEE Transactions on Sustainable Energy, 6(4), 1426-1434.

Sun, Q., Wu, J. \& Hu, Y. (2019). Cascaded multiport converter for SRM-Based Hybrid Electric Vehicle Applications, IEEE Transactions on Power Electronics, 34(12), 11940-11951. DOI: 10.1109/ TPEL.2019.2909187

Tazay, A. \& Miao, Z. (2018), Control of a Threephase Hybrid Converter For a PV Charging Station, IEEE Transactions on Energy Conversion, 33(3), 1002-1014. 
Venkatramanan, D. \& John, V. (2019). Dyamic Modeling and Analysis of Buck Converter based Solar PV Charger Controller for improved MPPT Performance, IEEE Transactions on Industry Applications, 55(6), 6234-6246.

Vyas, A., Santini, D., Duoba, M. \& Alexander, M. (2008). Plug-in Hybrid Electric Vehicles: How does one determine their potential for reducing US Oil dependence, World Electric Vehicle Journal, 2, 38-56. DOI: https://doi.org/10.3390/wevj2010038
Yan, Q., Zhang, B. \& Kezunovic, M. (2017). Optimized Operational Cost Reduction for an EV Charging Station Integrated With Battery Energy Storage and PV Generation, IEEE Transactions on Smart Grid, 10(2), 2096-2106.

Zhou, Y., Ho, C. N. M. \& Siu, K. K. (2019). A Fast PV MPPT Scheme using Boundary Control with Second-Order Switching Surface, IEEE Journal of Photovoltaics, 9(3), 849-857. 